\title{
AWARENESS AND WILLINGNESS TO CONSUME WHOLE PLANT-BASED FOOD IN IBADAN NORTH LOCAL GOVERNMENT AREA OF OYO STATE, NIGERIA
}

\author{
APPAH, N.E ${ }^{\mathbf{1}}$, ADEOSUN, K.P P, $^{1, *}$ AND OMONONA, B.T ${ }^{1}$ \\ ${ }^{I}$ Department of Agricultural Economics, University of Ibadan, Ibadan, Nigeria \\ ${ }^{2}$ Department of Agricultural Economics, University of Nigeria, Nsukka, Nigeria \\ *Corresponding author's email: paul.adeosun@unn.edu.ng, \\ Adeosun: https://orcid.org/0000-0002-8061-5851
}

\begin{abstract}
Food is an essential entity that supports life and is required in the right quantity and quality in all living things which includes man and animals. Food contains nutrients which would be used in the body of an organism to sustain growth, aid vital processes and to furnish energy. Even though some foods are important for growth and development, the factors influencing households to purchase is yet unknown in the literature. More so, low consumption of plantbased food can lead to poor nutrition which impairs daily health and wellbeing. Thus, this study examines factors that influencing the willingness to consume plant-based whole foods. Data were obtained from primary source from households in Ibadan, Oyo State through the use of structured questionnaire with the adoption of multistage sampling procedure. Data were analysed using the Descriptive Statistics, Ordinary Least Squares Regression Model, Logistic Regression, Probit Regression Model. The findings from the study show that marital status, educational level and household size are the important determinants of the level of awareness of whole plant-based diet by households. Likewise, results show that marital status, education and income are the variables that influence the willingness of households to consume whole plant food. The study concludes that the consumption of whole plant-based foods is of great benefit to households as the prevalence of non-communicable diseases would be drastically reduced. The study recommends that households should be educated on the benefits of whole plant food through focused group discussion and media channels to increase the willingness to consume it. Government should place taxes on highly processed food to discourage their purchase and consumption.
\end{abstract}

Key words: Socioeconomic determinants, Plant-based food, Non-communicable diseases,

\section{https://dx.doi.org/10.4314/jafs.v19i2.8}

\section{INTRODUCTION}

Food, an essential entity that supports life is required in the right quantity and quality in all living things which includes man and animals. Food contains nutrients which would be used in the body of an organism to sustain growth, aid vital processes and to furnish energy. The absorption and utilization of food by the body and its digestion is fundamental to good health. Though the field of medicine continues to advance and branch out in many ways, nutritionists and health experts continue to praise the benefits of certain foods. In fact, eating healthily has been shown to reduce the

Journal of the Faculty of Agriculture and Veterinary Medicine, Imo State University Owerri website: www ajol.info 
Journal of Agriculture and Food Sciences

Volume 19, Number 2, October 2021, pp $\quad 75-85$

risk of obesity, cardiovascular illnesses and even certain types of cancer (Nkomoke et al., 2019).

The key driver for eating is of course hunger but what we choose to eat is determined solely by our physiological or nutritional needs. Some of the factors influencing food choice include: biological determinants such as taste and appetite, economic determinants such as cost, income and availability; physical determinants such as access, education, skills (e.g. cooking) and time; social determinants such as culture, family, peers and meal patterns; and psychological determinants such as mood and stress, attitude, beliefs and knowledge about food (Kabir et al., 2018). The consumption of food plays a role in determining the amount of nutrients to be derived from it (Molika and Mobley, 2019).

Poor nutrition can impair our daily health and wellbeing and reduce our ability to lead an enjoyable and active life. In the short term, poor nutrition can contribute to stress, tiredness and our capacity to work. Over time, it can contribute to the risk of developing some illnesses and other health problems such as: being overweight or obese, high blood pressure, high cholesterol, heart diseases and stroke, diabetes, eating disorders, cancer and a range of health problems which are prevalent in this present century (World Health Organization, 2004). To reduce and avoid health problems related to food consumption, it is advised that humans practice healthy dietary practices early in life (WHO, 2011).

An effective way of achieving healthy dietary practice is the consumption of food items which are beneficial and an example of this is the whole food plant-based diet. Whole food plant-based diet (WFPBD) is a diet consisting mostly or entirely of foods derived from plants including vegetables, grains, roots and tubers, nuts, seeds, legumes, fruits and with few or no animal products. Whole food plantbased diet contains all essential nutrients with
Appah, N.E., Adeosun, K.P. and Omonona, B.T. ${ }^{76}$

the exception of Vitamin B12 and in the proportion that is more appropriate for to human needs (Carlos et al., 2019).

Non-communicable diseases (NCDs) are increasingly becoming the leading causes of morbidity and mortality worldwide World Health Organization, 2004. They encompass a cluster of illnesses which include: diabetes mellitus, cancer, chronic respiratory diseases, cardiovascular disease and musculoskeletal disorders. They are now seen to affect the poor of the poorest countries in the world and the impact is greatest on the poor countries of sub-Saharan Africa of which Nigeria occupies a significant position (Ekpenyong et al., 2012).Non-communicable diseases are the number one world's killer, causing $60 \%$ of all deaths globally and a staggering 35 million people die every year from these silent killers, of which 18 million are women (HCC-NCD Alliance, 2011). In 2018, this figure rose to 36.1 million (about $63 \%$ of global deaths) and nearly $80 \%$ of those NCD deaths-equivalent of 29 million people occurred in low- and middle-income countries with the projection of about 52 million deaths annually by 2030 (WHO, 2011). Diabetes, obesity, cancer and the other non-communicable diseases have been seen to have a link to what is being consumed by man.

In Nigeria, the impact of NCDs is enormous and glaring. In 2012, about 8 million Nigerians suffered from hypertension and 4 million from diabetes with 100,000 new cases of cancer being diagnosed each year in Nigeria (Wasiu and Towobla, 2013). About 5 million Nigerians were projected to have died of NCDs as at 2015 and diabetes alone was projected to have caused about $52 \%$ of the mortality (Wasiu and Towobla, 2013). The Lancet (2018) revealed $71.3 \%$ of deaths in 2015 were caused by dietary and lifestyle choices as compared to only $57.6 \%$ in 1990. NCDs do not just occur at a particular instance of consumption of unhealthy food; it

\section{Journal of the Faculty of Agriculture and Veterinary Medicine, Imo State University Owerri}

website: www ajol.info 
is a gradual minute by minute and day by day death of the body cells as a result of unhealthy food consumption. What most people do not realize is that almost every physical problem they experience other than accidents have a diet related cause. Food like processed dairy products, processed fruits, refined grains, meat, certain oils, certain seasoning (refined table salt), canned soups, sweets and processed vegetables should be well avoided in the human diet in order to live a healthy life (UNICEF, 2019). More so, low consumption of plant-based food can lead to poor nutrition which impairs daily health and wellbeing. Based on the foregoing, the study aim to analyse factors that promote or constrain extent of consumption of whole foods plant-based diet, awareness of whole foods plant-based diet and willingness to consume more of whole foods plant-based diet.

\section{MATERIALS AND METHODS \\ Study Area}

Ibadan North is a Local Government Area in Oyo State, Nigeria. Its administrative headquarters stands at Agodi, Ibadan. It is one of the five Local Government Areas carved out of the defunct Ibadan Municipal Government in 1991. The local government area covers a landmass of 132,500 square kilometres with a population density of 2,626 persons per square kilometre (NPC, 2006). The Local Government Area is bound by Akinleye and Lagelu LGA to the North, Egbeda Local Government to the East, Ibadan North West to the west and Ibadan North East to the south. There is little or no serious farming activities in the area being an urban centre. Trading and other commercial activities are predominant in the area. Ibadan North Local Government Area is subdivided into twelve (12) wards. It is a metropolitan community and it is the most populated in the state. Major residential areas in the LGA include: Bodija (old and new), Total garden, Oritamefa, Aladorin, Yemetu, Agbowo,
Samonda, Sango, Oremeji, Mokola, Idiape and Oke Are.

\section{Data Collection}

Primary data were collected with the use of a structured questionnaire. The questionnaire were administered to the head of household. The target group comprised household heads with different cultural and religious backgrounds, age group, educational level, marital status, household size, occupation and income level. Data were collected from household heads which were either male or female on their socioeconomic characteristics, dietary type awareness, food consumption pattern, expenditure on food, accessibility to food items, changes in dietary pattern and reason for change, health status of entire household and their willingness to increase consumption of whole foods plant-based diet and/or decrease in unwholesome food.

\section{Sampling Procedure}

A multi-stage sampling procedure was adopted for this study. The first stage was the random selection of two wards out of the twelve wards in the Local Government. Thereafter, the residential areas in the wards were categorized into low, middle and highclass residential areas based on their standard of living and infrastructural facilities available in the area. Two residential areas were selected from each of the classes, making a total of six (6) residential areas. The selected areas include: Agbowo and Sango for low class, Cocacola and Mokola for middle class and Old Bodija and New Bodija for high class residential areas. In the final stage, forty households were selected from each of the selected residential areas making a total of 240 household heads selected for this study, see Table 1.

\section{Model specification}

Ordinary Least Squares (OLS) Model

Ordinary Least Squares regression was adopted in determining the consumption of

\section{Journal of the Faculty of Agriculture and Veterinary Medicine, Imo State University Owerri} website: www ajol.info 
Journal of Agriculture and Food Sciences

Volume 19, Number 2, October 2021, pp $75-8.5$

whole foods by the households in the study area.

In a linear regression model, the response variable $y_{i}$ is a linear function of the regressors:

$$
y_{i}=\beta_{0}+\beta_{1} x_{i 1}+\beta_{2} x_{i 2}+\ldots \beta_{p} x_{i p}+i
$$

Where, $y_{i}=$ Consumption of whole plant foods per month defined as:

$=\frac{\text { Whole plant food expenditure in naira }}{\text { Total food expenditure in naira }}$

$\beta_{i}=$ parameters or coefficients to be evaluated

$\mathrm{i}=$ error term

$\mathrm{X}_{\mathrm{i}}=$ Explanatory variable $\mathrm{i}(\mathrm{i}=1$

$\mathrm{X}_{1}=$ Age of household head in years

$\mathrm{X}_{2}=$ Years of formal education of household head

$\mathrm{X}_{3}=$ Sex of household heads (1 if Male, 0 if female)

$\mathrm{X}_{4}=$ Marital status of household head (1 = Married, $0=$ Otherwise)

$\mathrm{X}_{5}=$ Income of household in Naira (months)

$\mathrm{X}_{6}=$ Occupation $($ Farming $=1$, Otherwise $=0$ )

$\mathrm{X}_{7}=$ Location $(0=$ Low income areas, $1=$ Middle income areas, $3=$ High income areas)

$\mathrm{X}_{8}=$ Household size

\section{Logistic model}

Logistic regression was used in determining the level of awareness of whole plant food by households.

This study adopts the log odds approach to predict or explain the awareness of whole food plant-based lifestyle by households (1 if aware, 0 otherwise) based on the evaluations of the factors influencing them.

$Y_{\mathrm{i}}^{*}=\beta_{0}+\beta_{1} \mathrm{X}_{1 \mathrm{i}}+\ldots \varepsilon_{\mathrm{i}}$

Journal of the Faculty of Agriculture and Veterinary Medicine, Imo State University Owerri website: www ajol.info
Appah, N.E., Adeosun, K.P. and Omonona, B.T. 78

Where $\mathrm{Y}_{\mathrm{i}}^{*}=$ Awareness of plant-based diet by households ( 1 if aware, 0 otherwise)

$\beta_{I i}=$ parameters or coefficients to be estimated

$\varepsilon_{i}=$ error term

$X_{i}=$ vector of explanatory variables

For determining the awareness of households on whole plant foods lifestyle, the explanatory variables include:

$X_{1}=$ Age of household head in years

$\mathrm{X}_{2}=$ Years of formal education of household head

$\mathrm{X}_{3}=$ Sex of household heads $($ Male $=1$, Female $=0$ )

$\mathrm{X}_{4}=$ Income of household head in naira

$\mathrm{X}_{5}=$ Location $(0=$ Low income areas, $1=$ Middle income areas, $3=$ High income areas)

$\mathrm{X}_{6}=$ Household size

$\mathrm{X}_{7}=$ Occupation $($ Farming $=1$, Otherwise $=0$ )

$\mathrm{X}_{8}=$ Marital status $(1=$ Married, $0=$ Otherwise)

\section{Probit Regression Model}

Probit regression model was employed to determine the factors influencing willingness to consume whole foods plant-based diet.

$y_{i}^{*}=\beta_{0}+\beta_{1} x_{1-8}+\varepsilon_{i}$

$\varepsilon_{\mathrm{i}} \sim \mathrm{N}\left(0, \sigma^{2}\right)$

$\mathrm{Y}=$ Willingness to consume whole plant food

$\mathrm{X}=$ factors influencing willingness

$\mathrm{X}_{1}=$ Sex of household head (Male $=1$, Female $=0$ )

$\mathrm{X}_{2}=$ Age of household head

$\mathrm{X}_{3}=$ Years of education of household head

$\mathrm{X}_{4}=$ Income of household (Naira)

$\mathrm{X}_{5}=$ Household size 
Journal of Agriculture and Food Sciences

Volume 19, Number 2, October 2021, pp $75-85$

$\mathrm{X}_{6}=$ Occupation $($ Farming $=1$, Otherwise $=0$ )

$\mathrm{X}_{7}=$ Marital status $(1=$ Married, $0=$ Otherwise)

$\mathrm{X}_{8}=$ Location $(0=$ Low income areas, $1=$ Middle income areas, $3=$ High income areas)

\section{RESULTS AND DISCUSSION}

Factors Influencing the Consumption of Whole Plant Food

Table 2 shows the result of the ordinary least squares regression using the double log model of the factors influencing the consumption of whole plant-based food in the study area. The lead equation was chosen based on statistical and econometric criteria as it had the best fit among the models (linear, semi-log, double $\log$ and exponential). The model has the highest R-squared value, lowest mean sum of squares residual among the four models and also with the highest number of significant explanatory variables. The model is statistically significant at $1 \%$ probability level has $F$ value of 13.148; coefficient of multiple determination of $37.3 \%$. From the result, the income, household size, primary occupation and education level were statistically significant at $1 \%, 5 \%, 5 \%$ and $10 \%$ probability level respectively. Educational level of household head is statistically significant (at $10 \%$ probability level) and negative relationship $(-0.233)$ with the consumption of whole plant food. This means that the more educated the household heads are, the less the consumption share of whole plant food and vice versa. This may be because of exposure to different types of processed or they nature of food store in the living environment. However, this is against our apriori expectation and against the study of Ali and Rahut (2019) where it was observed that as the educational level of household heads increase, the more informed they are and consume more of healthy foods. The primary occupation of household head is statistically significant (at 5\% probability Journal of the Faculty of Agriculture and Veterinary Medicine, Imo State University Owerri website: www ajol.info level) and negative relationship (-0.206) with the consumption of whole plant-based food. This indicates that household heads who have occupation other than farming, consume more of whole plant food than those whose primary occupation is farming. This is against the study of Lampietti et al. (2009) who stated that people whose occupation is farming will likely increase the consumption of whole foods. This implies that farmers may also want to copy the lifestyles of the affluent by tending to consume highly processed food and animal food also or they may want to sell their produce to buy processed foods. Regarding household income, income is statistically significant (at $1 \%$ probability level) and positive relationship (0.478) with the consumption of whole plant food. The positive relationship indicates that as the income of household head increases, there is an increase in the consumption share of whole plant food by the households. This is due to the ability of higher income earners being able to afford whole plant-based food even if they are costly. The household size is statistically significant (at $5 \%$ probability level) and positive relationship with the consumption of whole plant-based food. This means that as the size of the household increases, the consumption shares of whole plant food increases.

\section{Determinants of the Awareness of Household Heads of Whole Food Plant- Based Diet}

Table 3 presents the result of the logistic regression of the factors determining the awareness of whole plant-based food in the study area. The marital status of household head is significant (at 5\% probability level) and with marginal effect of -0.033 . This means that the marital status (married) of household heads decreases the probability of being aware of whole plant-based food by $3.3 \%$. This opposes the study of Hakli et al. (2016) where it was noted that being married increases the probability of being aware of 
Journal of Agriculture and Food Sciences

Volume 19, Number 2, October 2021, pp 75-85

wholesome food. Education of household head is significant (at 5\% probability level) and with a marginal effect of 0.019 . This indicates that the educational level of household head increases the probability of being aware of whole plant food by $1.9 \%$. This means that being an educated household makes him or her source for more information about healthy foods. This is in line with the results of the study of Crawford, Worsely and Lea (2006) where it was stated that as the level of education of household heads increases, the awareness of whole plant food would also increases, this is because more learned household heads would be informed about the benefits of a plant-based diet and this also increases the probability of adoption. The size of household is significant (at 10\% probability level) and with a marginal effect of 0.090. This means that the size of household increases the probability of being aware of whole plant food by $9 \%$, this is because different household member source or receive information about plant-based foods. This depict that household will have more information on the nutritive and healthwise importance of plant-based foods. More so, large household will be pre-occupied with how to meet the food needs of the family while also considering the nutritional needs of majority of the household members. This is in line with the study of Alkerwi et al. (2015) who analysed the relationship between nutritional awareness and diet quality.

Factors influencing the Willingness of Households to Consume More of Whole Food Plant Based Diet

Table 4, shows results of the factors influencing the willingness of households to consume more of whole food plant-based diet using Probit Regression Model. The marital status of household head is significant at $1 \%$ and has a marginal effect of 0.029 , which indicates that the marital status (married) of the household heads increases the probability of the willingness of households to increase
Appah, N.E., Adeosun, K.P . and Omonona, B.T.

consumption of whole plant food by $2.9 \%$. This shows that the household heads with their spouses want the best for their family members in terms of the nutritional content of what is being consumed. This is in line with the study of Haghjou et al. (2013).Education of household head is statistically significant (at 5\% probability level) and with a marginal effect of 0.024, which means that the educational level of the household heads increases the probability of household's willingness to consume more of whole plant food by $2.4 \%$. This indicates that the more educated the household heads are, the more willing they would be in consuming more of whole plant food. This is because they may have the knowledge of health benefit of plantbased foods. This is in line with the study of Kearney et al. (2000) that education is indispensable factor in the selection of healthy foods. Income of household head is statistically significant (at $5 \%$ probability level) and has a marginal effect of 0.031 which means that the income of household head increases the probability of household's willingness to consume more of whole plant food would also increase. This means that household head will have to increase their allocation on foods particularly plant-based foods. This is due to the fact that the households can afford to purchase fresh wholesome food at any point in time for consumption.

\section{Reported Illnesses by Households Based on their Consumption Share of Wholesome Food in their Diet}

The most prevalent reported illnesses among households in the study area are stroke, diabetes, diarrhoea, typhoid, ulcer, high blood pressure, cancer, obesity, ulcer, goitre and arthritis. These reported illnesses were tabulated with the consumption share of wholesome food by the households which were categorized into proportions. The table 5 shows the percentages of households which

\section{Journal of the Faculty of Agriculture and Veterinary Medicine, Imo State University Owerri website: www ajol.info}


Journal of Agriculture and Food Sciences

Volume 19, Number 2, October 2021, pp 75 - 85

experience the various diseases based on their consumption share of whole plant food.

$\mathrm{Q}_{1}=$ Consumption of less than $25 \%$ of whole plant food in diet

$\mathrm{Q}_{2}=$ Consumption of $25-49.9 \%$ of whole plant food in diet

$\mathrm{Q}_{3}=$ Consumption of $50-74.9 \% \%$ of whole plant food in diet

$\mathrm{Q}_{4}=$ Consumption of $75-100 \% \%$ of whole plant food in diet

Taking diabetes for example, households which consumed less than $25 \%$ of whole plant food in their diet reported more prevalence of diabetes $(41.67 \%)$ than households whose diet consist of more than $75 \%$ of whole plantbased food, only $13.89 \%$ of them (households whose diet had $>75 \%$ of wholesome food) recorded diabetes as an illness they experience and this might be as result of not totally being on the whole plant food diet.

It is observed that households which consume a high percentage share of wholesome foods reported lesser prevalence of noncommunicable diseases and households which consume a lesser share of wholesome food reported more prevalence of noncommunicable diseases. This is in line with result of the study by Drewnowski and Rehm (2015) also in line with the study of Olumakaiye et al. (2010) where analysis revealed that people who ate healthy meals had lower chances of being overweight while those who consumed a meal with two snacks (unwholesome food) daily had the highest prevalence of being overweight.

\section{CONCLUSION}

In this study, three elements of consumption of whole plant-based were considered:- share of expenditure, awareness and reported illness. Different factors were examined with respect to these elements to see the important factors promoting or constraining them. From the findings, it is established that educational
Appah, N.E., Adeosun, K.P . and Omonona, B.T. 81

level of household heads, income of household heads, primary occupation of household head and household size are indispensable factors when it comes to the consumption of whole plant-based foods. It is further established that the marital status of household head, educational level of household head and the household size determine the awareness of whole food plantbased diet by households. Similarly, it was established that the income of household head, marital status of household head and the educational level of the household head are important determinants of willingness of households to consume more of whole plant food. It was also discovered that households which had higher percentage consumption of whole plant food recorded less prevalence of reported illnesses in the study area, as against those whose consumption level of whole plant was lower. It has been revealed from the study that an increased consumption of wholesome food would reduce the occurrence of non-communicable diseases among households and this would be of an advantage to individuals, households and the country as a whole. Therefore, the following policy recommendations are suggested and advised to be implemented:

1. Households should be educated on the benefits of whole plant food through focused group discussion and media channels.

2. Taxes on highly processed food such as should be increased as this will discourage their purchase and consumption due to increased prices.

3. Income is a strong determinant in the food consumption pattern of the population; therefore, the government should organise special social interventions and empowerment programmes aimed at providing economic protection to low income earners who spend a bulk of their income on food consumption.

\section{Journal of the Faculty of Agriculture and Veterinary Medicine, Imo State University Owerri website: www ajol.info}


Journal of Agriculture and Food Sciences

Volume 19, Number 2, October 2021, pp 75-85

\section{REFERENCES}

Ali, A \& Rahut, D.B. (2019). Healthy Foods as Proxy for Functional Foods: Consumers' Awareness, Perception and Demand for Natural Functional Foods in Pakistan. International Journal of Food Science. 1: 1-13.

Alkerwi, A. (2015). Association Between Nutritional Awareness and Diet Quality. Journal of Nutrition 7: 2823-2838.

Carlos, A.M., Geoffrey, C., Mark, L., Maria, Laura, C.L., \& Priscilia, P.M. (2019). Ultra-processed foods, diet quality and health using NOVA classification system. Food and Agriculture Organization of the United Nations.

Crawford D., Lea., E \& Worsley, A. (2006). Public Views of the Benefits and Barriers to the Consumption of a Plant-Based Diet. European Journal of Clinical Nutrition 60, 828-837.

Drewnowski, A. \& Rehm, C.D. (2015). Socioeconomic Gradient in Consumption of Whole Fruit and 100\% Fruit Juice Among United States Children and Adults. Nutritional Journal 14(3): 58-87

Ekpenyong ,C.E., Udokang, N.E., Akpan, E.E. \& Samson, T.K. (2012). NonCommunicable Diseases and Risk Factors Evaluation in Sub-Saharan Africa: The Nigerian Experience. European Journal of Sustainable Development 2(1):249-270.

Haghjou, M., Hayati, B. \& Pishbahar, E. (2013). Factors Affecting Consumers' Potential Willingness to Pay for Organic Food Products in Iran. Journal of Agricultural Science 15(2): 191-202.

Hakli, G., Asli, U., Ozdogan, Y. \& Yilmaz, M. (2016). Nutritional Knowledge and Behaviour of Adults: Their Relations with Sociodemographic Factors. Journal of Nutrition 10:532-539.
Appah, N.E., Adeosun, K.P. and Omonona, B.T.

Healthy Carribean Coalition (HCC) NCD Alliance (2011). Non-Communicable Disease Poverty for Women's Health and Development. Available at http://www.iumsp.ch/Enseignement/collo ques/do.

Kabir, A, Miah, S, \& Islam, A. (2018). Factors influencing eating behaviour and dietary intake among resident students in a public university in Bangladesh: A qualitative study. https://doi.org/10.1371/journal.pone.0198 801

Kearney M., Kearney J.M., Dunne A. \& Gibney M.J. (2000). Sociodemographic Determinants of Perceived Influences of Food Choice in a Nationally Representative Sample of Irish Adults. Public Health Nutrition 3:219-226.

Lampietti, J.A., Lugg, D.A., Van Der Celen P., \& Branczik A. (2009). The changing face of rural space: agriculture and rural development in the Western Balkans. World Bank, Washington D.C.

Molika, C. \& Mobley, A. (2019). Factors Associated with Identification and Consumption of Whole Grain Foods in A Low-Income Population. Current Developments in Nutrition 3(7): 64-93

National Population Commission (NPC), (2006). The Nigeria Population Census

Nkomoki, W., Bavorova, M. \& Banout, J. (2019): Factors Associated with Household Food Security in Zambia. Journal of Food Sustainability 11(1): 1-18

Olumakaiye, M.F. (2010). Food consumption patterns of Nigerian adolescents and effect on body weight. Journal of Nutrition Education and Behaviour. 42(3): 144-151.

United Nations Children's Fund (UNICEF), (2019). Children, Food and Nutrition: Growing Well in A Changing World. 
Volume 19, Number 2, October 2021, pp 75 - 85

Wasiu, A. \& Towobla S.K. (2013). Pattern of Fast Food Consumption and Contribution to Nutrient Intake of Nigerian University Students. International Journal of Education and Research. 1(5): 1-10.

World Health Organization (WHO), (2004). Comparative Qualification of Health Risks: Global and Regional Burden of
Disease Attributable to Selected Major Risk Factors. Geneva, World Health Organization.

World Health Organization (WHO), (2011). Non-Communicable Disease Trend in all Countries, World Health Global Report, World Health Organization. 
Journal of Agriculture and Food Sciences

Appah, N.E., Adeosun, K.P. and Omonona, B.T. 84

Volume 19, Number 2, October 2021, pp 75 - 85

\section{APPENDIX}

Table 1. Total Sample Size

\begin{tabular}{lll}
\hline Residential Classes & Selected Residential Areas & Selected Household Heads \\
\hline Low & Agbowo and Sango & 80 \\
Middle & Cocacola and Mokola & 80 \\
High & Old Bodija and New Bodija & 80 \\
\hline Total & & 240 \\
\hline
\end{tabular}

Table 2. Ordinary Least Square (Double log) Results of Factors Influencing the Consumption of Whole Plant Food

\begin{tabular}{lllll}
\hline Variables & Coefficient & Std error & P-value & t-value \\
\hline Sex of household head & 0.343 & 0.229 & 0.135 & 1.50 \\
Marital Status & 0.087 & 0.094 & 0.356 & 0.93 \\
Educational level & $-0.233^{*}$ & 0.120 & 0.053 & -1.95 \\
Primary occupation & $-0.206^{* *}$ & 0.090 & 0.023 & -2.29 \\
Income & $0.478^{* * *}$ & 0.077 & 0.000 & 6.24 \\
Household size & $0.205^{* *}$ & 0.092 & 0.027 & 2.23 \\
Age of household head & 0.007 & 0.184 & 0.970 & 0.04 \\
Constant & -3.836 & 0.940 & 0.000 & -4.08 \\
\hline R-squared & 0.373 & Number of obs & 240 \\
F-test & 13.148 & Prob $>$ F & & 0.000 \\
Akaike crit. (AIC) & 313.421 & Bayesian crit. (BIC) & 339.227 \\
\hline$* * * 0.01, * * p$
\end{tabular}

$* * * p<0.01, * * p<0.05, * p<0.1$

Source: Field Survey, 2020

Table 3 Results of Logistic Regression Showing Factors Determining the Awareness of Whole Food Plant Based Diet

\begin{tabular}{lcccccc}
\hline Awareness & Marginal effect & Coefficient & Standard Error & P-Value & z-value \\
\hline Sex -0.065 & -0.354 & 0.356 & 0.320 & -0.99 \\
Marital status & -0.033 & & $-0.690^{* *}$ & 0.373 & 0.065 & -1.85 \\
Education Level & 0.019 & $0.469^{* *}$ & 0.208 & 0.024 & 2.26 \\
Primary Occupation & -0.024 & -0.042 & 0.097 & 0.664 & -0.43 \\
Household Size & 0.090 & $-0.164^{*}$ & 0.092 & 0.074 & -1.79 \\
Age & -0.011 & -0.006 & 0.011 & 0.601 & -0.52 \\
Income & 0.043 & $1.92 \mathrm{e}-07$ & $1.95 \mathrm{e}-06$ & 0.921 & 0.10 \\
Constant & & 0.691 & 0.832 & 0.406 & 0.83 \\
\hline Pseudo R-Squared & 0.404 & \multicolumn{5}{c}{ Number of obs. 240} \\
Chi-Square & 14.68 & Prob> Chi2 0.040 \\
\hline
\end{tabular}

$* * * p<0.01$ (significant at 1\%), $* * p<0.05$ (significant at $5 \%$ ), $* p<0.1$ (significant at $10 \%$ )

Source: Field Survey, 2020

Journal of the Faculty of Agriculture and Veterinary Medicine, Imo State University Owerri website: www ajol.info 
Journal of Agriculture and Food Sciences

Appah, N.E., Adeosun, K.P. and Omonona, B.T. 85

Volume 19, Number 2, October 2021, pp 75 - 85

Table 4: Result of Probit regression showing factors that influence the willingness of households to consume more of whole plant food

\begin{tabular}{lccccc}
\hline Willingness & Marginal effect & Coefficient & Standard Error P-Value & t-value \\
\hline Sex & 0.046 & 0.094 & 0.124 & 0.446 & 0.76 \\
Marital status & 0.029 & $0.059^{* * *}$ & 0.032 & 0.069 & 1.83 \\
Education & 0.024 & $0.030^{* *}$ & 0.011 & 0.007 & 2.70 \\
Primary Occupation & 0.028 & 0.037 & 0.039 & 0.343 & 0.95 \\
Household Size & 0.009 & 0.103 & 0.079 & 0.198 & 1.29 \\
Age & 0.007 & 0.017 & 0.063 & 0.787 & 0.27 \\
Income & 0.031 & $-0.015^{* *}$ & 0.039 & 0.070 & -0.39 \\
Constant & -0.393 & 0.317 & 0.217 & -1.24 & \\
\multicolumn{5}{c}{ Number of obs. 240 } \\
Pseudo R-Squared & 0.303 & \multicolumn{5}{c}{ Prob> Chi2 0.075} \\
Chi-Square & 14.27 & &
\end{tabular}

$* * * p<0.01$ (significant at $1 \%$ ), $* * p<0.05$ (significant at $5 \%$ ), $* p<0.1$ (significant at $10 \%$ )

Source: Field Survey, 2020

Table 5: Assessing the consumption share of wholesome food in comparison with household reported illnesses based on the proportion of wholesome food consumed in their diet.

\begin{tabular}{lllll}
\hline Diseases & $\mathbf{Q}_{\mathbf{1}}(<\mathbf{2 5 \%})$ & $\mathbf{Q}_{\mathbf{2}} \mathbf{( 2 5 - 4 9 . 9 \% )}$ & $\mathbf{Q}_{\mathbf{3}} \mathbf{( 5 0 - 7 4 . 9 \% )}$ & $\mathbf{Q}_{\mathbf{4}}(\mathbf{7 5 \% )}$ \\
\hline Stroke & 53.33 & 20 & 20 & 6.7 \\
Diabetes & 41.67 & 22.22 & 22.22 & 13.89 \\
Cancer & 42.86 & 42.85 & 14.29 & 0 \\
Typhoid & 42.11 & 30.53 & 18.94 & 8.42 \\
Diarrhea & 30.07 & 42.31 & 16.67 & 10.25 \\
Obesity & 40.00 & 40.000 & 20.00 & 0 \\
Goiter & 57.14 & 42.86 & 0 & 0 \\
Arthritis & 52.38 & 23.81 & 14.29 & 9.52 \\
Ulcer & 36.66 & 31.67 & 25 & 6.67 \\
High blood & 44.29 & 22.86 & 17.14 & 15.71 \\
pressure & & & & \\
\hline
\end{tabular}

Source: Field Survey, 2020.

Journal of the Faculty of Agriculture and Veterinary Medicine, Imo State University Owerri website: www ajol.info 